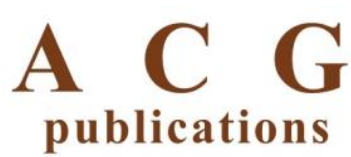

Rec. Nat. Prod. 14:4 (2020) 269-275

records of natural

products

\title{
Bioactive Constituents from the Rhizomes of Sansevieria cylindrica
}

\author{
Hnin Thanda Aung ${ }^{1 *}$, Mya Mu Aye $\oplus^{1}$, Zaw Min Thu $\oplus^{2}$, \\ Yumiko Komori ${ }^{4}$ Myint Myint Sein $\oplus^{1}$, Giovanni Vidari $\oplus^{3}$ and \\ Yoshiaki Takaya $\oplus^{4 *}$
}

\author{
${ }^{1}$ Department of Chemistry, University of Mandalay, Mandalay, Myanmar \\ ${ }^{2}$ Department of Chemistry, Kalay University, Kalay, Myanmar \\ ${ }^{3}$ TIU Research Center, Tishk International University, Erbil, Iraq \\ ${ }^{4}$ Faculty of Pharmacy, Meijo University, Nagoya, Japan
}

(Received October 10, 2019; Revised December 12, 2019; Accepted December 13, 2019)

\begin{abstract}
Analysis of the $\mathrm{MeOH}$ extract of rhizomes of Sansevieria cylindrica using repeated silica gel and reversed-phase chromatographic separations led to the isolation of ten known phenolic compounds (1-10) belonging to five different classes. Their structures, including the absolute configuration, were identified by NMR and CD spectra analysis. The antiradical activity of isolated compounds was screened using the DPPH scavenging method. The cytotoxic effects were assayed against a Hela cell line. Compounds 2-10 have been isolated from a Sansevieria species for the first time and compounds 5, 7-10 have been isolated from species of the Asparagaceae family for the first time. The structure of a homoisoflavanone isolated from S. roxburghiana has been revised.
\end{abstract}

Keywords: Sansevieria cylindrical; Asparagaceae; homoisoflavanone; cynnamoyl octopamine; tyramine derivatives; antiradical activity. (C2020 ACG Publication. All right reserved.

\section{Introduction}

The genus Sansevieria consists of about 70 species of flowering plants which are broadly distributed from Africa through Asia, including Myanmar and the islands of the Indian Ocean [1]. The genus Sansevieria was formely classified as belonging to the Dracaenaceae family. This family, however, has been included in the Asparagaceae by the APG III system of plant taxonomy for flowering plants (angiosperms), which is mostly molecular-based [2]. S. cylindrica Bojer ex Hook. is native to the subtropical African regions, and it is cultivated in Myanmar for ornamental purposes. It is also used as a traditional remedy, especially in remote rural areas of the country, where herbal preparations are still widely employed as medicines in the place of rarely available western drugs. The whole plant is employed for curing cuts, sprains and broken bones, whereas the roots are used to cure snakebites. Sansevieria plants have been reported to be rich in steroidal sapogenins and saponins. Previous phytochemical investigations of leaves and aerial parts of S. cylindrica led to the isolation of steroidal saponins [3-5], one of which demonstrated inhibition of capillary permeability activity [3], whereas others exhibited moderate cytotoxicities in vitro [4,5]. In addition, (+)-trifasciatine B, with

\footnotetext{
* Corresponding author: E-Mail: hninthandaaung07@gmail.com; Phone:95-977-333-8904

*Corresponding author: E-Mail: ytakaya@meijo-u.ac.jp; Phone: +81-52-8392740, Fax: +81-52-834-8090
} 
high radical scavenging activity activity [4], and dihydrochalcone (+)-trifasciatine $\mathrm{C}[5,6]$, showing a moderate cytotoxicity against MCF7 cells, were isolated.

In our ongoing research on new bioactive constituents from medicinal plants collected in Myanmar [7], a new homoisoflavanone, together with four known congeners and dihydrochalcone (-)-trifasciatine C, were recently isolated from the methanolic extract of S. cylindrica rhizomes [8]. Upon completion of our investigation on this plant, in this paper we describe the isolation and the structure identification of ten additional compounds. They include two homoisoflavanones, (-)trifasciatine A (1) [9] and (-)-(3R)-cambodianol (2) [10], one phenylpropane derivative, hydroxychavicol [3,4-dihydroxyallylbenzene (APC)] (3) [11], three alkaloids, trans- $N$ - $p$-coumaroyl tyramine [synonyms, $N$-( $p$-hydroxyphenyl)ethyl $p$-hydroxycinnamide and paprazine] (4) [12], (-)trans- $N$ - $p$-coumaroyl octopamine (5) [13], and (-)-trans- $N$-feruloyl octopamine (6) [14]. Two furanoflavones, lanceolatin B (7) [15] and pongaglabol methyl ether (8) [16], one 3-methoxyflavone, de(s)methoxy kanugin (9) [17], and one pterocarpan, (-)-(6aR,11aR)-homopterocarpin (10) [18-20], were also isolated by repeated chromatographic separations on silica-gel and reversed-phase RP-18 columns. The structures of isolated compounds (Figure 1), including the absolute configuration, were identified by analysis of DART-HRMS, IR, NMR and CD spectra, and comparison with the literature. The antiradical properties of the isolated compounds were screened by a standard DPPH test. The cytotoxic effects of compounds 1, 3, 4-6 and $\mathbf{1 0}$ towards Hela cells were assayed in a standard MTT test.<smiles>[R2]c1ccc(CC2([R])COc3c([Y])c([R2])c([R])c([R])c3C2=O)cc1[R20]</smiles><smiles>C=CCc1ccc(O)c(O)c1</smiles><smiles>[R]c1cc(/C=C/C(=O)NCC([Z1])c2ccc(O)cc2)ccc1O</smiles>

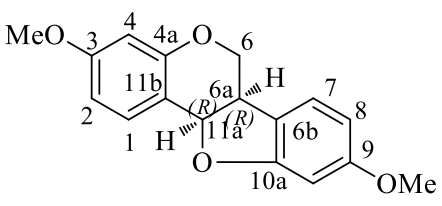

10

Figure 1. Chemical structures of compounds 1-10 isolated from Sansevieria cylindrica

\section{Materials and Methods}

\subsection{General}

UV spectra were recorded in MeOH on a JASCO V-560 UV-VIS spectrophotometer. IR spectra were recorded using $\mathrm{KBr}$ pellets on a JASCO FT/IR-410 spectrophotometer. Optical rotations were measured on a JASCO P-2200 polarimeter. CD spectra were recorded on a JASCO J-725 circular dichroism spectrometer. ${ }^{1} \mathrm{H}$ - and ${ }^{13} \mathrm{C}$-NMR spectra were recorded in $\mathrm{CDCl}_{3}$ or in methanol- $d_{4}$ on a Bruker Avance III HD600 spectrometer equipped with Prodigy liquid nitrogen cryoprobe. Chemical shifts for ${ }^{1} \mathrm{H}$ and ${ }^{13} \mathrm{C}$ NMR are given in ppm $(\delta)$ relative to TMS signal $\left(\delta_{\mathrm{H}} 0.00\right)$ and solvent signal $\left(\delta_{\mathrm{C}}\right.$ 77.0 for $\mathrm{CDCl}_{3}$ and 49.0 for methanol- $d_{4}$, respectively) as internal standards. Coupling constants $(J)$ are in Hz. Positive mode DART-HRMS data were obtained by using an Exactive Plus instrument (Thermo Scientific). Column chromatographic separations were carried out on silica gel (BW-820MH, Fuji Silysia, Aichi, Japan). Analytical TLC was performed on precoated silica gel $60 \mathrm{~F}_{254}$ plates (Merck, Darmstadt, Germany, Art. 5715). Spots were visualized under UV light at $254 \mathrm{~nm}$ and by spraying with anisaldehyde-sulfuric acid reagent, followed by heating at $200{ }^{\circ} \mathrm{C}$ for $2 \mathrm{~min}$. 
Semipreparative HPLC separations were performed on a chromatograph equipped with multiwavelength detector (JASCO) using a Develosil ODS UG-5 column $(\phi 20 \times 250 \mathrm{~mm}$, Nomura Chemical, Japan) and TSKgel ODS-120T ( $\phi 7.8 \times 300 \mathrm{~mm}$, Tosoh, Japan).

\subsection{Plant Material}

Rhizomes of Sansevieria cylindrica Bojer ex Hook. (Asparagaceae) were collected in September 2016 at Thazi Township in Mandalay Region, Myanmar. The plant was identified by Professor Dr Soe Myint Aye, Department of Botany, University of Mandalay, Myanmar. A voucher specimen (N-11) has been deposited at the Department of Chemistry, University of Mandalay, Myanmar.

\subsection{Extraction and Isolation}

Air-dried rhizomes of $S$. cylindrica $(1.0 \mathrm{Kg})$ were percolated with $\mathrm{MeOH}(4 \mathrm{~L})$ for two weeks. The whole mixture was then filtered through filter paper and the filtrate was evaporated in vacuo at room temperature to provide a sticky residue $(109 \mathrm{~g})$, which was partitioned between EtOAc, $\mathrm{H}_{2} \mathrm{O}$ and $n$ - $\mathrm{BuOH}$. The three layers were then evaporated in vacuo, separately, to provide residues A $(9.1 \mathrm{~g}), \mathrm{B}$ $(24.9 \mathrm{~g})$, and C (74.9 g), respectively. Subsequently, residue A was partitioned between $n$-hexane and $\mathrm{MeCN}$ at room temperature which, by evaporation in vacuo, afforded residues $\mathrm{D}$ (4.31 g) and E (4.36 g), respectively. Residue $\mathrm{E}$ was separated by flash column chromatography over octadecylsilanized silica gel (ODS). Elution with a gradient of $\mathrm{MeCN}$ in $\mathrm{H}_{2} \mathrm{O}$ (from 70:30, v/v, to $100 \% \mathrm{MeCN})$ gave 30 main fractions (E1-E30). Fractions E4 $(124 \mathrm{mg})$ and E12 (191 mg) were separated by semiprep. HPLC. Elution of the former with a gradient mixture of $\mathrm{MeOH}-\mathrm{H}_{2} \mathrm{O}(2: 98$, $\mathrm{v} / \mathrm{v})$ and $\mathrm{MeOH}$, from 9:1 to 8:2 (v/v) yielded compounds $5(5 \mathrm{mg})$ and $\mathbf{6}(2.9 \mathrm{mg})$. Elution of E12 $(191 \mathrm{mg})$ using a gradient mixture of $\mathrm{MeOH}-\mathrm{H}_{2} \mathrm{O}(2: 98, \mathrm{v} / \mathrm{v})$ and $\mathrm{MeOH}$, from 7:3 to 3:7 (v/v), afforded compounds $\mathbf{1}(3.8 \mathrm{mg})$ and $\mathbf{2}(5.0 \mathrm{mg})$. Flash column chromatography of fraction E13 (105 $\mathrm{mg}$ ) over octadecylsilanized silica gel (ODS) using a gradient mixture of $\mathrm{MeOH}-\mathrm{H}_{2} \mathrm{O}(2: 98$, v/v) and $\mathrm{MeOH}$, from 7:3 to 3:7 (v/v), gave compounds $8(1.5 \mathrm{mg})$ and $9(2.8 \mathrm{mg})$. Semiprep. HPLC separation of fraction E6 $(379.9 \mathrm{mg}), \mathrm{E} 8(415.4 \mathrm{mg}), \mathrm{E} 14(253 \mathrm{mg})$, and E15 $(67.3 \mathrm{mg})$ using a gradient mixture of $\mathrm{MeOH}-\mathrm{H}_{2} \mathrm{O}(2: 98, \mathrm{v} / \mathrm{v})$ and $\mathrm{MeOH}$, yielded compounds $4(2.2 \mathrm{mg}), \mathbf{3}(8.6 \mathrm{mg}), 7(1.6 \mathrm{mg})$, and $\mathbf{1 0}$ $(10.8 \mathrm{mg})$, respectively. Although (-)-(6aR, 11aR)-homopterocarpin (10) is a known plant metabolite [18-20], we were unable to find a complete list of physical and spectroscopic data. Therefore, they are reported below for completeness.

\subsection{1. (-)-(6aR,11aR)-homopterocarpin (10)}

Colorless crystals from EtOH; mp. $86-88^{\circ} \mathrm{C} ;[\alpha]_{\mathrm{D}}^{27}-205.71\left(c 0.03, \mathrm{CHCl}_{3}\right) ; \mathrm{CD} \lambda_{\max }(\mathrm{MeCN}) \mathrm{nm}$ $(\Delta \varepsilon): 238$ (-23.02), 288 (+9.95). UV $\lambda_{\max }(\mathrm{MeOH}) \mathrm{nm}(\log \varepsilon): 205$ (4.91), 229 (4.17), 286 (3.97). IR $v_{\max } \mathrm{cm}^{-1}$ 3396, 3070, 2937, 2835, 1619, 1496, 1444, 1346, 1276, 1199, 1159, 1031, 949, 834, 795, 631. DART-HRMS: $m / z 285.1120[\mathrm{M}+\mathrm{H}]^{+}$(calcd. for $\left.\mathrm{C}_{17} \mathrm{H}_{17} \mathrm{O}_{4} 285.1127\right) .{ }^{1} \mathrm{H}$ NMR $\left(\mathrm{CDCl}_{3}\right): \delta 7.42$ $(1 \mathrm{H}, \mathrm{d}, J=8.5 \mathrm{~Hz}, \mathrm{H}-1), 7.13(1 \mathrm{H}, \mathrm{d}, J=8.8 \mathrm{~Hz}, \mathrm{H}-7), 6.63(1 \mathrm{H}, \mathrm{dd}, J=2.6,8.5 \mathrm{~Hz}, \mathrm{H}-2), 6.5(1 \mathrm{H}, \mathrm{d}$, $J=2.6 \mathrm{~Hz}, \mathrm{H}-4), 6.45(1 \mathrm{H}, \mathrm{dd}, J=2.3,8.8 \mathrm{~Hz}, \mathrm{H}-8), 6.44(1 \mathrm{H}, \mathrm{d}, J=2.3 \mathrm{~Hz}, \mathrm{H}-10), 5.52(1 \mathrm{H}, \mathrm{d}, J=$ $6.8 \mathrm{~Hz}, \mathrm{H}=11 \mathrm{a}), 4.25(1 \mathrm{H}, \mathrm{dd}, J=5.3,10.9 \mathrm{~Hz}, \mathrm{C}-6 \mathrm{eq}), \delta 3.78(3 \mathrm{H}, \mathrm{s}, 3-\mathrm{OMe}), \delta 3.77(3 \mathrm{H}, \mathrm{s}, 9-$ OMe), $3.64(1 \mathrm{H}, \mathrm{t}, J=10.9 \mathrm{~Hz}, \mathrm{C}-6 \mathrm{ax}), 3.54$ (1H, m, C-6a). ${ }^{13} \mathrm{C}$ NMR (chloroform- $d$ ): 161.3 (s, C-9), 161.1 (s, C-3), 160.7 (s, C-10a), 156.6 (s, C-4a), 131.8 (d, C-1), 124.7 (d, C-7), 119.1 (s, C-6b), 112.4 (s, C-11b), 109.2 (d, C-2), 106.4 (d, C-8), 101.6 (d, C-4), 96.9 (d, C-10), 78.6 (d, C-11a), 66.6 (t, C-6), 55.5 (q, C-3-OMe), 55.4 (q, C-9-OMe), 39.6 (d, C-6a).

\subsection{Cytotoxicity Assay}

Cytotoxic effects of isolated compounds against a HeLa (cervix adenocarcinoma) cell line were assayed by the MTT colorimetric method using a Cell Counting kit-8 that was based on the tetrazolium salt/formazan system [21]. HeLa cells (JCRB9004) were obtained from the Japanese Collection of Research Bioresources (JCRB) cell bank. Cells were cultured in minimum essential 
media (MEM) supplemented with $10 \%$ fetal bovine serum. For the cytotoxicity assay, cells were seeded at a density of $5 \times 10^{3}$ cells/well in $0.2 \mathrm{~mL}$ of medium in 96-multiwell plates and adhered. Subsequently, samples were dissolved in saline containing $10 \%$ DMSO and sterilized by filtration. Subsequently, series of diluted samples $(0.2 \mathrm{~mL})$ were added to the cells. The plates were incubated under a humid atmosphere of $5 \%(v / v) \mathrm{CO}_{2}$ and $95 \%(v / v)$ at $37^{\circ} \mathrm{C}$ for $48 \mathrm{~h}$. Twenty microliters of cell counting kit-8 (based on the tetrazolium salt/formazan system) were added to each well, and the microplates were incubated for $1 \mathrm{~h}$, after which cell densities were measured at $450 \mathrm{~nm}$ using a BioRAD Model 550 Microplate Reader. Cisplatin was used as the cytotoxic reference compound.

\subsection{Radical Scavenging Activity Assay}

Antiradical effects of isolated compounds were assayed by the DPPH scavenging activity test. A total of $500 \mu \mathrm{L}$ of test solution at various concentrations (1-100 $\mu \mathrm{M}), 500 \mu \mathrm{L}$ of $0.2 \mathrm{M}$ acetate buffer $\mathrm{pH} 5.5$, and $1000 \mu \mathrm{L}$ of HPLC-grade EtOH were mixed in a test tube for water soluble compounds. For EtOH soluble compounds, $1000 \mu \mathrm{L}$ of test solution at various concentrations $(1-100 \mu \mathrm{M})$ and 1000 $\mu \mathrm{L}$ of $0.1 \mathrm{M}$ acetate buffer $\mathrm{pH} 5.5$ were mixed in a test tube. $500 \mu \mathrm{L}$ of $5 \times 10^{-4} \mathrm{M}$ DPPH solution was added to the mixture which was then homogenized using a vortex in a dark place, shielded from UV light, and incubated for $30 \mathrm{~min}$ at room temperature. Subsequently, the UV absorbance $(A)$ of the mixture at $517 \mathrm{~nm}$ was measured using a spectrophotometer. Vitamin $\mathrm{C}$ was used as the reference antiradical compound in the same concentration range as the tested compounds. A control solution was prepared in the same manner as the test mixture. The free-radical-scavenging activity [AA\%] of each sample and the reference standard was determined according to the following formula: [AA\%] = $100-\left[\left(A_{\text {sample }}-A_{\text {blank }}\right) \times 100 / A_{\text {control }}\right]$, where $A_{\text {sample }}$ is the absorbance of the sample with DPPH, $A_{\text {blank }}$ is the absorbance of the sample without DPPH, and $A_{\text {control }}$ is the absorbance of DPPH ${ }^{\circ}$ in EtOH. The concentration $(\mu \mathrm{M})$ of the sample reducing $50 \% \mathrm{DPPH}\left(\mathrm{EC}_{50}\right)$ was determined by plotting the percentage of inhibition against the sample concentration.

\section{Results and Discussion}

The residue $\mathrm{E}$ from the EtOAc subextract of the $\mathrm{MeOH}$ extract of $S$. cylindrica rhizomes was subjected to flash column chromatography over octadecylsilanized silica gel (ODS) followed by repeated semipreparative HPLC separations to afford ten known compounds (1-10). The physical and spectroscopic data of 1-10 nicely matched those reported in the literature. While browsing literature reports, we found that a compound isolated from S. roxburghiana [22] was claimed to have the same structure as (-)-cambodianol (2), isolated from Dracaena cambodiana [10]. However, upon carefully examining the ${ }^{13} \mathrm{C}$ NMR resonances determined for the homoisoflavanone from $S$. roxburghiana [22], we found that they were similar to the ${ }^{13} \mathrm{C}$ NMR signals of homoisoflavanone 11, which was previously isolated from Liriope muscari [23] and S. cylindrica [8]. In contrast, the ${ }^{13} \mathrm{C}$ NMR data of the compound isolated from $S$. roxburghiana [22] were significantly different from those determined for cambodianol (2) [10], although the solvents were not the same.

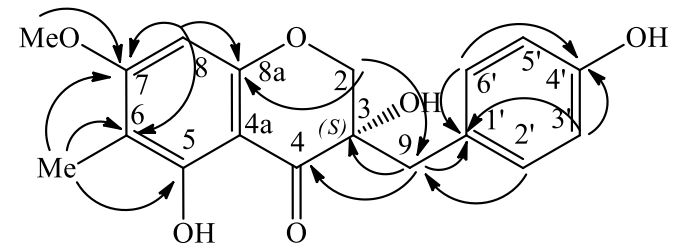

11

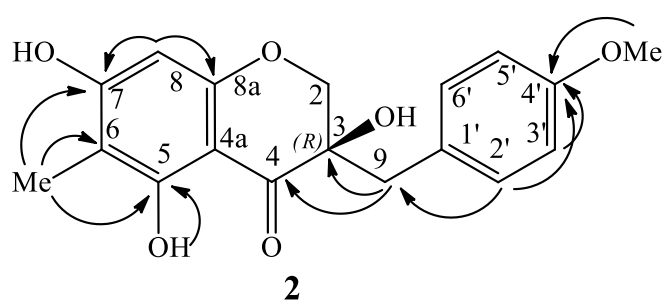

2

Figure 2. Representative HMBC correlations $(\mathrm{H} \rightarrow \mathrm{C})$ for compound $\mathbf{1 1}$ and $\mathbf{2}$ isolated from S. cylindrica

Compounds 2 and 11 were re-isolated from S. cylindrica during our investigations on this plant and their ${ }^{13} \mathrm{C}$ NMR spectra were determined in the same solvent, $\mathrm{CDCl}_{3}$ as the homoisoflavanone isolated from $S$. roxburghiana (Table 1). We reconfirmed that the structures of $\mathbf{2}$ and $\mathbf{1 1}$ are correct 
and are isomeric. In fact, the two compounds differ for the position of the methoxy group, which is at C-7 in compound 11 [8, 23] and at C-4' in cambodianol (2) [10]. Their location was confirmed by appropriate two bonds and three bonds correlations in the corresponding HMBC spectra (Figure 2) Moreover, comparison of the ${ }^{13} \mathrm{C}$ NMR spectra (Table 1) firmly indicated that the planar structure of the homoisoflavanone isolated from S. roxburghiana [22] must be revised from $\mathbf{2}$ to $\mathbf{1 1}$.

Table 1. ${ }^{13} \mathrm{C}$ NMR signals $\left(\delta_{\mathrm{C}} ; 150 \mathrm{MHz}, \mathrm{CDCl}_{3}\right)$ of compounds $\mathbf{1 1}$ and $\mathbf{2}$ isolated from $S$. cylindrica compared with literature

\begin{tabular}{ccccc} 
Carbon number & $\mathbf{1 1}^{\mathbf{a}, \boldsymbol{\varphi}}$ & $\mathbf{1 1}^{\mathbf{b}, \boldsymbol{*}}$ & Homoisoflavanone $^{\mathbf{c}, \boldsymbol{\Phi}}$ & $\mathbf{2}^{\mathbf{d}, \S}$ \\
\hline 2 & 71.9 & 71.9 & 72.0 & 71.8 \\
3 & 72.2 & 72.3 & 72.3 & 72.3 \\
4 & 198.3 & 198.3 & 198.3 & 198.3 \\
$4 \mathrm{a}$ & 100.1 & 100.2 & 100.2 & 100.3 \\
5 & 160.1 & 160.1 & 160.2 & 161.5 \\
6 & 106.5 & 106.5 & 106.6 & 104.5 \\
7 & 166.5 & 166.5 & 166.5 & 163.2 \\
8 & 90.9 & 91.0 & 91.0 & 95.0 \\
$8 \mathrm{a}$ & 161.1 & 161.1 & 161.1 & 160.6 \\
9 & 40.8 & 40.8 & 40.8 & 40.8 \\
$1^{\prime}$ & 126.4 & 126.2 & 126.2 & 126.2 \\
$2^{\prime} / 6^{\prime}$ & 131.8 & 131.8 & 131.8 & 131.6 \\
$3^{\prime} / 5^{\prime}$ & 115.2 & 115.3 & 115.3 & 113.8 \\
$4^{\prime}$ & 154.8 & 154.9 & 154.9 & 158.8 \\
$-\mathrm{OCH}_{3}$ & 55.9 & 56.0 & 56.0 & 55.2 \\
$-\mathrm{CH}_{3}$ & 6.9 & 6.9 & 6.9 & 6.7 \\
\hline
\end{tabular}

${ }^{\mathrm{a}}[8]$ and this paper; ${ }^{\mathrm{b}} 125 \mathrm{MHz}, \mathrm{CDCl}_{3}$ [23]; ${ }^{\mathrm{c}} 100 \mathrm{MHz}, \mathrm{CDCl}_{3}$ [22]; ${ }^{\mathrm{d}}$ this paper, 2: cambodianol

${ }^{\varphi}$ isolated from S. cylindrical; * isolated from Liriope muscari $;{ }^{\circledR}$ isolated from S. roxburghiana; ${ }^{\S}$ isolated from $S$. cylindrica

The $3 S$ configuration was attributed to compound (+)-11 isolated from Liriope muscari [23] and $S$. cylindrica [8]. The $3 R$ configuration has, instead, been proposed for the homoisoflavanone isolated from $S$. roxburghiana [22], whose stereostructure thus corresponds to that of ent-11. This finding is another example of enantiomeric congeners occurring in the same plant or in different species belonging to the same genus. Among homoisoflavanones arising from enantiodivergent biosynthetic pathways, other examples are trifasciatines B and C, whose enantiomers occur in $S$. cylindrica $[4,8]$ and in S. trifasciata [6,9], respectively. A couple of biosynthetic routes have been proposed to explain the formation of enantiomeric sappanin-type homoisoflavonoids, in which antipodal compounds evolve from achiral intermediates by divergent enantioselective reactions [8,9].

Homopterocapin (10), the three amides 4-6, trifasciatine A, and hydroxychavicol (3) showed no cytotoxicity $\left(\mathrm{IC}_{50}>80 \mu \mathrm{M}\right)$ against Hela cells in a standard MTT test [21]. The other isolated compounds could not be tested due to their insolubility in saline solution containing 10\% DMSO. In other experiments, significant cytotoxicities have been determined for cambodianol (2) [10], whereas hydroxychavicol (3) exhibited high antimicrobial, anti-inflammatory, and pancreatic lipase inhibitory effects [11]. On the other hand, lanceolatin B (7) showed high cancer chemopreventive potential [24], and anti-neuroinflammatory and analgesic properties [25]. In an antiradical screening test (DPPH) of compounds 1-10, hydroxychavicol (APC) (3) exhibited the highest scavenging activity $\left(\mathrm{EC}_{50}=2.33\right.$ $\mu \mathrm{M})$. Actually, the high antioxidant activity of APC has been demonstrated by different tests, including the prevention of $\mathrm{Fe}$ (II)-induced lipid peroxidation (LPO) of liposomes and rat brain homogenates as well as $\gamma$-ray-induced damage of pBR322 plasmid DNA [26]. (-)-trans- $N$-Feruloyl octopamine (6) showed moderate radical scavenging activity $\left(\mathrm{EC}_{50} 61.8 \mu \mathrm{M}\right)$, while the remaining isolated compounds displayed weak or no activity $\left(\mathrm{EC}_{50}\right.$ value $\left.>100 \mu \mathrm{M}\right)$; therefore, their antioxidant activity was no further investigated. 
In conclusion, rhizomes of $S$. cylindrica are a rich source of bioactive phenolic compounds, among which rare homoisoflavonoids form a distinctive subclass. Asparagaceae and Fabaceae families and, to a minor extent, Liliaceae, have been associated with the largest number of isolated homoisoflavonoids [27] and our results confirm this chemotaxonomic finding. A thorough survey of the literature has revealed that compounds $\mathbf{2 - 1 0}$ have been isolated from a Sansevieria species for the first time, and that this is the first finding of compounds 5, 7-10 in species belonging to the Asparagaceae family.

\section{Acknowledgments}

This work was supported by the bounty for academic research from the Research Institute of Meijo University. One of the authors (H.T.A.) is supported by Daiko Foundation research fellowship program 2016.

\section{Supporting Information}

Supporting information accompanies this paper on http://www.acgpubs.org/journal/records-ofnatural-products

\section{ORCID}

Hnin Thanda Aung: 0000-0002-6972-2381

Mya Mu Aye: 0000-0001-8694-398X

Zaw Min Thu: 0000-0002-2962-0006

Yumiko Momori: 0000-0002-0568-5796

Myint Myint Sein: 0000-0001-9963-3059

Giovanni Vidari: 0000-0003-4606-2154

Yoshiaki Takaya: $\underline{0000-0001-8634-6173}$

\section{References}

[1] R. Takawira and I. Nordal (2003). The genus of Sansevieria (Family Dracaenaceae) in Zimbabwe, Acta Hortic. 552, 629-633.

[2] Angiosperm Phylogeny Group III* (2009). An update of the Angiosperm Phylogeny Group classification for the orders and families of flowering plants: APG III, Bot. J. Linn. Soc. 161, 105-121.

[3] A.D.S. Antunes, B.P.D. Silva, J.P. Parente and A.P. Valente (2003). A new bioactive steroidal saponin from Sansevieria cylindrica, Phytother. Res. 17, 179-182.

[4] A. Said, E.A. Aboutabl, F.R. Melek, G.A.R:A. Jaleel and M. Raslan (2015). Steroidal saponins and homoisoflavanone from the aerial parts of Sansevieria cylindrica Bojer ex Hook., Phytochemistry Lett. 12, 113-118.

[5] M.A. Raslan, F.R. Melek, A.A. Said, A.L. Elshamy, A. Umeyama and M.M. Mounier (2017). New cytotoxic dihydrochalcone and steroidal saponins from the aerial parts of Sansevieria cylindrica Bojer ex Hook., Phytochemistry Lett. 22, 39-43.

[6] B.T. Tchegnitegni, R.B. Teponno, K. Jenett-Siems, M.F. Melzig, T. Miyamoto and L.A. Tapondjou (2017). A dihydrochalcone derivative and further steroidal saponins from Sansevieria trifasciata Prain, Z. Naturforsch. C 72, 477-482.

[7] Z.M. Thu, H.T. Aung, M.M. Sein, M. Maggiolini, R. Lappano and G. Vidari (2017). Highly cytotoxic xanthones from Cratoxylum cochinchinense collected in Myanmar, Nat. Prod. Commun. 12, 17591762.

[8] M.M. Aye, H.T. Aung, Z.M. Thu, M.M. Sein, Y. Takaya, Y. Komori, M. Clericuzio and G. Vidari (2018). Constituents of the rhizomes of Sansevieria cylindrica, Nat. Prod. Commun. 13, 1129-1132.

[9] B.T. Tchegnitegni, R.B. Teponno, C. Tanaka, A.F. Gabriel, L.A. Tapondjou and T. Miyamoto (2015). Sappanin-type homoisoflavonoids from Sansevieria trifasciata Prain, Phytochemistry Lett. 12, 262-266.

[10] J. Liu, W.L. Mei, J. Wu, Y.X. Zhao, M. Peng and H.F. Dai (2009). A new cytotoxic homoisoflavonoid from Dracaena cambodiana, J. Asian Nat. Prod. Res. 11, 192-195. 
[11] E. Kato, R. Nakagomi, M.D.P.T. Gunawan-Puteri and J. Kawabata (2013). Identification of hydroxychavicol and its dimers, the lipase inhibitors contained in the Indonesian spice, Eugenia polyantha, Food Chem. 136, 1239-1242.

[12] L. Treeratanapiboon, A. Worachartcheewan, T. Suksrichavalit, R. Kiatfuengfoo, S. Prachayasittikul, S. Ruchirawat and V. Prachayasittikul (2011). Bioactive 4-hydroxycinnamide and bioactivities of Polyalthia cerasoides, EXCLI Journal. 10, 16-22.

[13] J. Feng, M. Hu, Y.J. Jin, J.F. Cao, J.J. Jia, Y.T. Wanng and X.F. Li (2016). Radical scavenging constituents from leaf of Humulus scandens, Asian J. Chem. 28, 1820-1822.

[14] R.R. King and L.A. Calhoun (2005). Characterization of cross-linked hydroxycinnamic acid amides isolated from potato common scab lesions, Phytochemistry 66, 2468-2473.

[15] J.T. Mbafor, A.T. Atchade, A.E. Nkengfack, Z.T. Fomum and O. Sterner (1995). Furanoflavones from root bark of Millettia sanagana, Phytochemistry 40, 949-952.

[16] P. Anusiri (2013). Bioactive compounds from stem bark of Derris indica (Lamk.) Bennet. Thesis (M.Sc.) - Chulalongkorn University. http://doi.org/10.14457/CU.the.2013.147.

[17] B. Das, A.K. Chakravarty, K. Masuda, H. Suzuki and H. Ageta (1994). A diterpenoid from roots of Gelonium multiflorum, Phytochemistry 37, 1363-1366.

[18] Y-M Kan and R-D Wang (1994). Constituents of Glycyrrhiza pallidiflora, Fitoterapia 65, 91-94.

[19] M.J. Falcão, Y.B. Pouliquem, M.A. Lima, N.V. Gramosa, L.V. Costa-Lotufo, G.C. Militão, C. Pessoa, M.O. de Moraes and E.R. Silveira (2005). Cytotoxic flavonoids from Platymiscium floribundum, J. Nat. Prod. 68, 423-426.

[20] A. Goel, A. Kumar and A. Raghuvanshi (2013). Synthesis, stereochemistry, structural classification, and chemical reactivity of natural pterocarpans, Chem. Rev. 113, 1614-1640.

[21] M. Ishiyama, M. Shiga, K. Sasamoto, M. Mizoguchi and P. He (1993). A new sulfonated tetrazolium salt that produces a highly water-soluble formazan dye, Chem. Pharm. Bull. 41, 1118-1122.

[22] J. Roy, F. Aktar, M.R. Haq, B. Begum and C.M. Hasan (2013). A rare homoisoflavonoid cambodianol from Sansevieria roxburghiana, Asian J. Chem. 25, 5113-5114.

[23] W.J. Li, X.L. Cheng, J. Liu, R.C. Lin, G.L. Wang, S.S. Du and Z.L. Liu (2012). Phenolic compounds and antioxidant activities of Liriope muscari, Molecules 17, 1797-1808.

[24] R. Sharma, I.S. Williams, L. Gatchie, V.R. Sonawane, B. Chaudhuri and S.B. Bharate (2018). Furanoflavones pongapin and lanceolatin B block the cell cycle and induce senescence in CYP1A1overexpressing breast cancer cells, Biorg. Med. Chem. 26, 6076-6086.

[25] X. Xuo, L. Zhang, L. Gao, Y. Guo, L. Zhang, L. Li, J. Si and L. Cao (2015). Antiinflammatory and analgesic activities of ethanol extract and isolated compounds from Millettia pulchra, Biol. Pharm. Bull. 38, 1328-1336.

[26] J.S. Rathee, B.S. Patro, S. Mula, S. Gamre and S. Chattopadhyay (2006). Antioxidant activity of Piper betel leaf extract and its constituents, J. Agric. Food Chem., 54, 9046-9054.

[27] M.V. Castelli and S.N. López (2017). Homoisoflavonoids: Occurrence, Biosynthesis, and Biological Activity. In Studies in Natural Products Chemistry 54, 315-354. Elsevier B.V., Amsterdam NL.

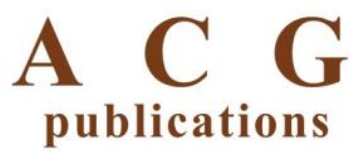

(C) 2020 ACG Publications 